PRODUCTION

ENGINEERING ARCHIVES
2014, Vol. 4, No. 3, pp 14-17

ISSN 2353-5156 (print version)

ISSN (online version)

Article history: Received: 27.05.2014 Accepted: 10.06.2014 Online: 01.10.2014

\title{
BRC/IoP standard importance in packaging quality assurance
}

\author{
Agnieszka Kawecka $^{1}$ \\ ${ }^{1}$ Packaging Department, Cracow University of Economics, Rakowicka 27, 31-510 Kraków, Poland, tel. +48 12 2935168, e-mail: \\ kaweckaa@uek.krakow.pl
}

\begin{abstract}
BRC/IoP (British Retail Consortium / Institute of Packaging) is the only industry standard dedicated entrepreneurs operating in the packaging industry, primarily intended for contact with food. The requirements of the BRC / IoP guarantee the safety of packaging and fulfillment of all legal and hygienic requirements. The article presents the main features of the standard, the basic requirements contained in the document and the results of research on the implementation of quality management systems, including standard BRC / IoP and the actions that are required checklists. It is noticeable that there is little interest in certification BRC / IoP, due to low awareness of the standard, despite the fulfillment of some of the basic requirements of the surveyed companies.
\end{abstract}

Key words - food and non-food packaging, packaging quality, BRC/IoP

\section{Introduction}

British Retail Consortium is an organization which associates retail enterprises from different sectors like: food, cosmetics, clothing and many others. Standards proposed by BRC are mainly addressed to retail company suppliers. Some retail companies require certification of BRC standard to become their supplier. The method of the co-operation with suppliers is an important part of the organization's operation (KAFEL P., NOWICKI P. SIKORA T. 2012). In standardized systems a model has been developed to ensure the ability to meet quality requirements and increase customer satisfaction (ULEWICZ R. 2013). According to ISO 9000, the organization and its suppliers are interdependent and a mutually beneficial relationship enhances the ability of both parties to create value (ISO 9000:2005).

That is why standards that are very popular are implemented in companies from 90 countries, BRC has issued more than 20000 certificates (GRIFFITHS J. 2011).

\section{Characteristics of BRC/IoP standard and its fundamentals}

The first BRC standard concerning packaging and packaging materials was published in 2001, in cooperation with the Institute of Packaging. The latest issue 4 became active on 1 August 2011. It is directly connected with issue 5 of the Global Standard for Food Safety, which is reflected in the newest version.

The standard is dedicated to packaging sector companies who produce packaging and packaging materials used in food and non-food industry. The main idea in creating the standard was to provide an efficient tool for packaging industry to ensure consumer safety and fulfillment of legal requirements. 
For the proper course of quality assurance of packaging and adequate system operation it is appropriate to determine of packaging hazard category. The new issue of the BRC/IOP Standard recognizes two categories of operation (Global Standard BRC/IoP):

- High Hygiene Risk: 'Packaging that comes into direct contact with food products or other designated hygiene-sensitive products. Primary packaging used for food or other hygiene-sensitive products where there is no absolute barrier in place'.

- Low Hygiene Risk: 'Packaging for consumer products and the secondary and tertiary packaging for all uses'.

A significant barrier should be considered in the risk of physical, chemical or microbiological contamination from the environment or packaging material itself into the product. This risk must be eliminated.

Appropriate definition of the packaging hazard category allows proper quality assurance packaging. The standard has determined different requirements for both categories. It is obvious that for high hygiene risk categories packaging requirements are stricter than low hygiene risk categories (CHOLEWA-WÓJCIK, LISIŃSKA-KUŚNIERZ 2012).

\section{Packaging quality assurance in BRC/IoP standard}

The standard is in the form of a check list. By adhering to the requirements included in checklists the organization is fulfilling legal requirements, assuring safety and quality of produced packaging materials and packaging. New to the fourth issue of the BRC/IOP Standard are:

- A grading system reflecting the number and the severity of non-conformances identified during the certification audit process.

- The introduction of 'Fundamental' Clauses to reflect the importance of operations crucial to an effective and safe packaging operation.

- Any major non-conformance raised against a statement of intent of a Fundamental Clause would not permit certification to take place.

The most important issues covered in standard are called "Fundamental Clauses" and they consider tasks such as: Senior Management Commitment, Hazard and
Risk Analysis, Internal Audits, Traceability, Housekeeping and Cleaning, Process Control, Training and Competency.

In every kind of quality management systems the important role is assigned to non-conformities and the methods of coping with them. In Global Standard $\mathrm{BRC} / \mathrm{IoP}$ non-conformities are divided into three types, taking into consideration their influence on safety or legal requirements fulfillment by the finished product. The grading of non-conformities is presented in Fig. 1.

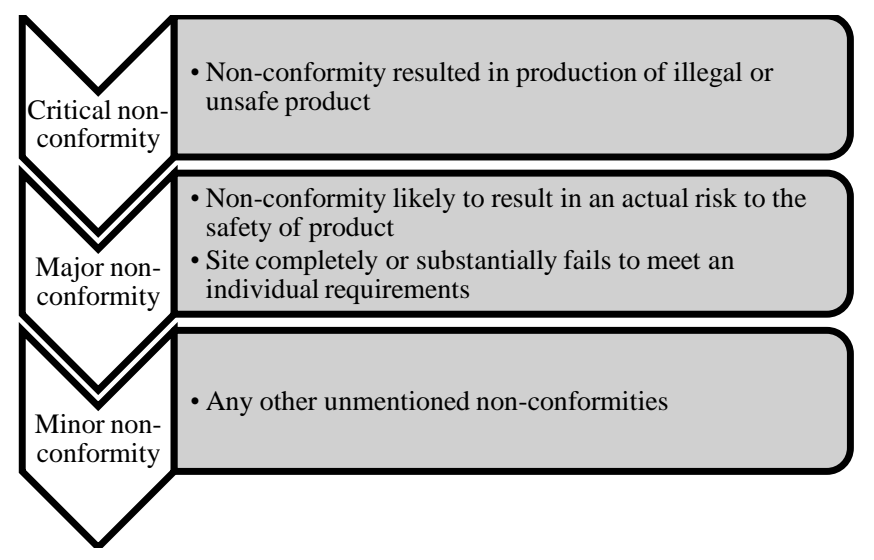

Fig. 1. Non-conformity grading

Source: own work on the basis of (Guide to Enrolment...)

The organization from the packaging sector with the implemented standard BRC/IOP has discovered many benefits (Introduction to $\mathrm{BRC} / \mathrm{IoP}$ ):

- existing implementation of a quality management system in accordance with IS0 9001 for many companies meant that many of the requirements of the standard was already met,

- cost savings made through improved efficiency and productivity,

- improvements developed, resulting in less waste, rejected work and fewer complaints,

- retailers and companies co-operating with them chose approved suppliers. 


\section{BRC/IoP requirements implementa- tion in Polish packaging sector}

On the basis of the survey undertaken in $100 \mathrm{com}$ panies from the Polish packaging sector, it might be suggested that Global Standard BRC/IoP is not very popular, research results are presented in Fig. 2.

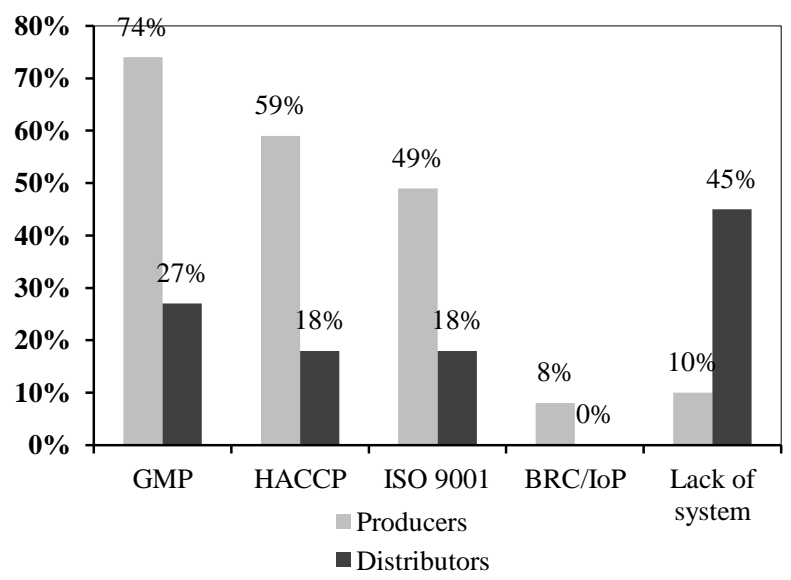

Fig. 2. Implementation of quality assurance and management systems in polish packaging sector

Source: own study

Only $8 \%$ of researched packaging manufacturers had implemented BRC/IoP. None of the researched packaging distributors has implemented a system based on this standard. Quality assurance and management systems like ISO 9001, HACCP and GMP are much more popular. It is a concern that $10 \%$ of producers and even $45 \%$ of distributors have not implemented any system. Generally, quality assurance and management systems are more frequent in production companies than service companies (LISIŃSKAKUŚNIERZ KAWECKA 2012).

In the course of research, companies were asked to indicate what kind of activities they carry out to assure proper packaging quality and safety. The selected results are presented in Fig. 3.

Activities such as: carrying out hazard analysis, keeping traceability records, housekeeping and cleaning, obeying production procedures, training of the personnel were chosen as the most consistent with fundamental of BRC/IoP Global Standard. Among manufacturers the most widespread are housekeeping and cleaning, keeping traceability records and carrying out production in accordance with procedures, all of them were conducted in more than $90 \%$ of researched companies. A lower degree of implementation is noticeable in activities like training of the personnel (87\%) and carrying out hazard analysis (77\%). Among distributors all activities are implemented on a lower level. The most implemented is keeping the distribution process in accordance with the procedure (82\%). On the same level are implemented activities like: carrying out hazard analysis, housekeeping and cleaning and training of personnel. The lower level of implementation is noticeable in keeping traceability record $(64 \%)$

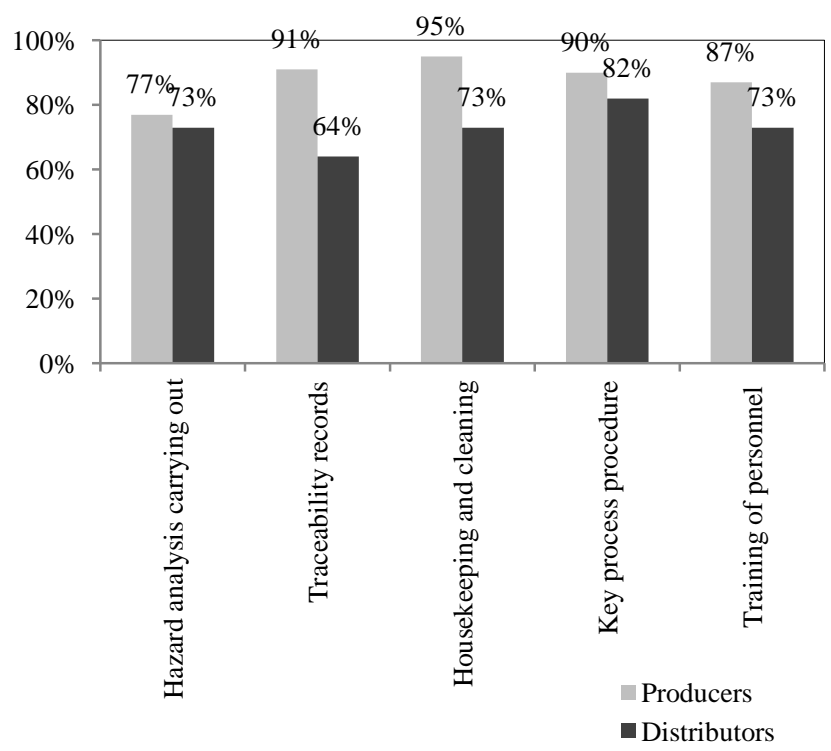

Fig. 3. Implementation of chosen actions assuring quality in companies

Source: own study

\section{Summary and conclusions}

Global Standard BRC/IoP is the first industrial standard dedicated to the packaging sector. It is a useful tool for companies from the packaging sector in building and improving their quality systems. The fundamentals of BRC/IoP requirements are compatible with quality management systems in accordance with ISO 9001 but they are strictly fitted to the packaging branch. Requirements concerning safety and quality correspond to legal requirements in this area. For many companies it might be facilitation, because standards like ISO 9001 are more general and require an individual approach. 
Global Standard BRC/IoP covers all important areas in packaging quality assurance. Moreover with particular emphasis on issues directly connected with food packaging, and other hygiene-sensitive product packaging, for example cosmetics, safety assurance. This regulation especially focuses on issues such as: Senior Management Commitment, Hazard and Risk Analysis, Internal Audits, Traceability, Housekeeping and Cleaning, Process Control, Training and Competency.

Despite these benefits BRC/IoP is not very popular and widespread in the Polish packaging sector. Senior management do not have an awareness about the existence of this industry standard. Although there is a low level of implementation and certification of BRC/IoP, a great share of packaging industry companies are conducting activities indicated in the standard requirements as fundamental. This standard is mainly implemented in companies which are suppliers for retailers, especially from Great Britain like Tesco. However, there is a need to emphasize its high suitability for the packaging sector. The popularity of all BRC standards is growing so it might be anticipated that $\mathrm{BRC} / \mathrm{IoP}$ will also become more prevalent in the packaging industry.

\section{Literature}

1. CHOLEWA-WÓJCIK A. LisiŃSKA-KuŚNIERZ M. 2012. Safety of Packaging Plastic Films Based on an Analysis of Changes in their Physical Properties During Storage and Use, In: Product and Packaging. Tendencies for Development in Manufacturing. Wyd. Politechniki Łódzkiej. Łódź, p. 101-112.

2. Global Standard BRC/IOP for Packaging and Packaging Materials 2011. Issue 4, British Retail Consortium, London.

3. GRIFFITHS J. 2011, BRC/IoP Global Standard for Packaging and Packaging Materials, BRC and GMP, www.polymersni.com/media/JGriffiths-\%20BRC.pptx, 18.04.2014.

4. Guide to Enrolment Program for BRC Global Standard for Packaging and Packaging Material Issue 42014. London.

5. Introduction to BRC/IoP Packaging British Retail Consortium Global Standard for Food Packaging http://www.standards.org/standards/listing/brc_iop_pac kaging\#TOC_Introduction. 18.04.2014.

6. ISO 9000:2005 Quality management system - Fundamentals and vocabulary

7. KAFEL P., NOWICKI P. SIKORA T. 2012. Wymagania dotyczace dostawców wybranych sieci spożywczych. Zarządzanie Jakością 3-4 (29-30). p. 20-23

8. LISIŃSKA-KUŚNIERZ M., KAWECKA A. 2013. The role of packaging supply chain in food packaging safety assurance. Logistics and Transport. Vol. 19, No 3, p. 37-44.

9. ULEWICZ R. 2013. Effectiveness assessment of functioning of quality assurance system, Production Engineering Archives. 1, p. 38-40. 